\title{
Cryopreservation of Schisandra chinensis (Turcz.) Baill callus and subsequent plant regeneration
}

\author{
D. Sun*, Y.-F. Yu*, H.-Y. Qin, P.-L. Xu, Y. Zhao, Y.-X. Liu, Z.-X. Wang, \\ S.-T. Fan, Y.-M. Yang and J. Ai \\ Institute of Special Wild Economic Animals and Plants, \\ Chinese Academy of Agricultural Sciences, Changchun, China \\ *The authors contributed equally to this study. \\ Corresponding author: J. Ai \\ E-mail: aijun1005@163.com
}

Genet. Mol. Res. 15 (4): gmr15049342

Received September 21, 2016

Accepted September 21, 2016

Published December 19, 2016

DOI http://dx.doi.org/10.4238/gmr15049342

Copyright $(C 2016$ The Authors. This is an open-access article distributed under the terms of the Creative Commons Attribution ShareAlike (CC BY-SA) 4.0 License.

\begin{abstract}
Cryopreservation has been proven significance as a technique for promising the long-term conservation of plant germplasms. This study aimed to establish a cryopreservation protocol for calli of Schisandra chinensis (Turcz.) Baill, and to explore the effects of different process parameters on callus viability. Effects of desiccation duration, cryoprotectants and cryopreservation methods, thawing temperature, and post-culture conditions on the viability of cryopreserved calli were assessed. Among different cryoprotectants and freezing procedures, the highest survival was recorded when the water content of callus after 30 min desiccation was $57.3 \%$, were loaded into a cryoprotectant containing $10 \%$ ethylene glycol, $8 \%$ glucose, and $10 \% \mathrm{DMSO}$, and frozen slowly $\left(-1{ }^{\circ} \mathrm{C} / \mathrm{min}\right)$. Rapid thawing at $40^{\circ} \mathrm{C}$ for 2 min demonstrated the best recovery of cryopreserved S. chinensis
\end{abstract}


calli. Post-culturing in darkness for one week before transfer to light conditions (under $16 \mathrm{~h}$ photoperiod at $36 \mu \mathrm{mol} \cdot \mathrm{m}^{-2} \cdot \mathrm{s}^{-1}$ ) was beneficial to callus regeneration. Plants regenerated through somatic embryogenesis from cryopreserved calli remained ploidy stable after cryopreservation. The callus cryopreservation procedure established in this study is a promising tool for the conservation of $S$. chinensis resources.

Key words: Resource conservation; Survival; Somatic embryogenesis; Stability

\section{INTRODUCTION}

Schisandra chinensis (Turcz.) Baill. is a type of woody, deciduous vine that grows mainly in northeastern Asia (China, Japan, and Korea) and eastern of Russia (Min et al., 2008). The fruits and stems of S. chinensis are listed by the Chinese Pharmacopoeia Commission as both food and herbal medicine, and have been widely used to treat various diseases, and as additions to functional foods (Chinese Pharmacopoeia Commission, 2010). According to the results of advanced pharmacological research, lignans, as the bioactive compounds in S. chinensis, could prevent conditions such as breast and thyroid cancers, heart disease, and hepatotoxicity (Ip and Ko, 1996; Hancke et al., 1999; Ohsugi et al., 1999; Chang et al., 2005; Li et al., 2005). However, owing to overexploitation, and a lack of organized cultivation, genuine populations have declined rapidly in their natural habitat (Zhang et al., 2007). Thus, development of S. chinensis germplasm resources for conservation is of ever-increasing necessity.

Traditionally, field genebanks have been used for the ex situ storage of endangered materials (Engelmann and Engels, 2002). However, there are some drawbacks, such as limits of function and threats to plant security (Withers and Engels, 1990; Engelmann, 1997). These storage resources are subject to pests and diseases, and any other natural disasters, such as flood, weather damage, vandalism, and human error. Besides, they are not beneficial for germplasm exchange, due to the great risks of disease cross-infection between plant species (Lambardi et al., 2001; Engelmann and Engels, 2002). Recently, efficient cryopreservation techniques have been developed and applied to a great number of plant species. To allow vitrification of water inside cells during sample cooling, freezable tissue water was often eliminated by osmotic dehydration during pre-treatment (Engelmann, 2012). For cryopreservation, the callus was usually used, because its cells are relatively undifferentiated (Popova et al. 2009). Although cryopreservation retains the genetic and phenotypic performance of materials, and permits long-term storage of plant tissues (Reed, 2002; Menges and Murray, 2004), it's necessary to evaluate the genetic integrity of plant cells after cryopreservation (Harding, 2004). Flow cytometric analysis of nuclear DNA content indicated genomic instability of some plant species, such as Taxus x media and Taxus floridana (Baebler et al., 2005; Škrlep et al., 2008).

Basic research on the somatic embryogenesis of $S$. chinensis has been performed in our lab, but cryopreservation for tissue culture has not been reported to date. In this study, we are the first to describe the successful cryopreservation and storage of $S$. chinensis calli. To select the most useful cryopreservation method, we investigated the effects of desiccation duration, cryoprotectants and cryopreservation methods, thawing temperature, and postculture conditions on the viability of cryopreserved calli from S. chinensis. Furthermore, relative nuclear DNA content of the regenerated plant was determined.

Genetics and Molecular Research 15 (4): gmr15049342 


\section{MATERIAL AND METHODS}

\section{Plant material and calli induction}

Tender stems of $S$. chinensis were collected from a base at the Institute of Special Animal and Plant Sciences, Chinese Academy of Agricultural Sciences, Jilin, China, in July 2014. The explants were washed in running water for $30 \mathrm{~min}$, soaked in $75 \%(\mathrm{v} / \mathrm{v})$ ethanol for $30 \mathrm{~s}$, sterilized with $0.1 \%(\mathrm{w} / \mathrm{v}) \mathrm{HgCl}_{2}$ solution for $5 \mathrm{~min}$, and then rinsed four to five times with sterile water. The stems were cut into $5 \mathrm{~mm}$ pieces and inoculated on MS (Murashige and Skoog) basal medium (Murashige and Skoog, 1962), supplemented with $3.0 \mathrm{mg} \cdot \mathrm{L}^{-1}$ 2,4-dichlorophenoxyacetic acid (2,4-D), $0.2 \mathrm{mg} \cdot \mathrm{L}^{-1}$ thidiazuron (TDZ), and $3 \%(\mathrm{w} / \mathrm{v})$ sucrose for callus induction.

\section{Desiccation procedure}

After 2 months' incubation, calli were cut into 2-3 mm squares, and placed on sterile filter paper to remove residual water. Desiccation was initiated by placing calli clumps on open Petri dishes inside a clean bench with a flow of sterile air for 0-60 min. Temperature during desiccation was controlled to $25^{\circ} \pm 1{ }^{\circ} \mathrm{C}$, and remained stable among treatments. To find the suitable desiccation time, the level of water loss was determined. Five clumps were sampled and weighed after every 30 min of desiccation. To ensure survival with the residual water content at each stage, desiccated calli were put in $1.8 \mathrm{~mL}$ cryotubes (Nunc, Denmark) with $10 \%$ ethylene glycol, $8 \%$ glucose, and $10 \%$ DMSO for 20 min at room temperature, and then transferred to liquid nitrogen (LN). After 24-h cryopreservation, calli were rewarmed in $40^{\circ} \mathrm{C}$ water and then washed twice with liquid MS containing 3\% sucrose. The calli were cultured on solid MS with $3.0 \mathrm{mg} / \mathrm{L}$ 2,4-D and $30 \mathrm{~g} / \mathrm{L}$ sucrose, maintained at $25^{\circ} \pm 1^{\circ} \mathrm{C}$ in darkness for 1 week, and then moved to light conditions (under 16-h photoperiod at $36 \mu \mathrm{mol} \cdot \mathrm{m}^{-2} \cdot \mathrm{s}^{-1}$ ). Survival rate was determined as the number of new tissues formed around calli clumps after 5-week treatment, and expressed as a percentage.

\section{Cryoprotectants and freezing procedures for callus}

Four types of cryoprotectants (S1: plant vitrification solution 2 [PVS2; Sakai et al., 1990]; S2: $10 \%$ DMSO and 10\% sorbitol; S3: $12.5 \%$ DMSO and $0.25 \%$ casein hydrolysate [CH]; S4: 10\% ethylene glycol, $8 \%$ glucose, and 10\% DMSO) and three freezing methods were used for cryopreservation. Cryoprotectants were prepared and autoclaved at $121^{\circ} \mathrm{C}$ for $15 \mathrm{~min}$. Two callus clumps were placed in $1.8 \mathrm{ml}$ cryotubes (Nunc, Denmark) with different cryoprotectants for $20 \mathrm{~min}$ at room temperature, and then cryopreserved using different processes. For fast freezing, the cryotubes were directly placed in LN. For step-wise freezing, the cryotubes were first placed in a refrigerator at $4^{\circ} \mathrm{C}$ for $30 \mathrm{~min}$, and then transferred to $-20^{\circ} \mathrm{C}$ for $30 \mathrm{~min}$, and finally placed in LN. For slow freezing, the cryotubes were put in a $\mathrm{Mr}$. Frosty device (Nalgene), containing isopropyl alcohol as a coolant, and a cooling rate of $1^{\circ} \mathrm{C} /$ min down to $-80^{\circ} \mathrm{C}$ was reached. Cryotubes with the samples were then placed in LN.

\section{Callus recovery and viability}

Rewarming was performed at $4{ }^{\circ} \mathrm{C}$ in a refrigerator or $25^{\circ} \mathrm{C}$ (room temperature) or

Genetics and Molecular Research 15 (4): gmr15049342 
at $40^{\circ} \mathrm{C}$ in a water bath. Thawed calli were then rinsed twice with liquid MS containing $3 \%$ sucrose. After rewarming, the calli were cultured on MS with $3.0 \mathrm{mg} / \mathrm{L} \mathrm{2,4-D}$ and $3 \%$ $(\mathrm{w} / \mathrm{v})$ sucrose for proliferation, in one of the following four ways: a) cultured under a 16-h photoperiod at $36 \mu \mathrm{mol} \cdot \mathrm{m}^{-2} \cdot \mathrm{s}^{-1}$ without a dark period; b) cultured for 3 days in dark, then under a continuing $16-\mathrm{h}$ photoperiod at $36 \mu \mathrm{mol} \cdot \mathrm{m}^{-2} \cdot \mathrm{s}^{-1} ; \mathrm{c}$ ) cultured for 1 week in darkness, then under a continuing $16 \mathrm{~h}$ photoperiod at $36 \mu \mathrm{mol} \cdot \mathrm{m}^{-2} \cdot \mathrm{s}^{-1} ; \mathrm{d}$ ) cultured for 2 weeks in darkness, then under a continuing $16 \mathrm{~h}$ photoperiod at $36 \mu \mathrm{mol} \cdot \mathrm{m}^{-2} \cdot \mathrm{s}^{-1}$.

\section{Somatic embryogenesis and plant regeneration}

Calli were subcultured after 2 months, and after successive subculturing twice more, calli were cut into $0.5 \times 0.5 \mathrm{~cm}$ squares and moved to embryogenic callus induction medium, which consisted of MS with $1.0 \mathrm{mg} / \mathrm{L} \mathrm{TDZ}, 0.2 \mathrm{mg} / \mathrm{L}$ Zeatin $(\mathrm{Zt})$ and $3 \%(\mathrm{w} / \mathrm{v})$ sucrose. Induction of somatic embryos was performed on $1 / 2 \mathrm{MS}$. Somatic embryos were cultured on $1 / 2 \mathrm{MS}$ after 1 month for maturation, and cotyledon embryos were then transferred to $1 / 2 \mathrm{MS}$ with $1 \mathrm{~g} / \mathrm{L}$ activated carbon and $3 \%(\mathrm{w} / \mathrm{v})$ sucrose for germination.

\section{Determination of relative nuclear DNA content}

Relative nuclear DNA content was analyzed with a PAS III flow cytometer (Partec, Munster, Germany). Plants regenerated from cryopreserved calli, and plants regenerated from calli without cryopreservation were ground with $300 \mu \mathrm{L}$ extraction buffer (CyStain UV Precise P, Partec $\mathrm{GmbH}$ ), and placed at $25^{\circ} \mathrm{C}$ for $10 \mathrm{~min}$. The nuclear extracts were filtered (30 $\mu \mathrm{L}$ paste, CellTrics, Partec $\mathrm{GmbH}$ ) into $5-\mathrm{mL}$ plastic tubes, and then $1.2 \mathrm{~mL}$ staining buffer (CyStain UV Precise P) was added. After $60 \mathrm{~s}$, the samples were analyzed with the PAS III flow cytometer.

\section{Statistical evaluation}

In this study, at least 20 calli clumps were used in each of three replicates. The data variance (ANOVA) was analyzed with SPSS 22.0 (SPSS Inc., Chicago, IL, USA) for Windows. Significantly different means were compared using Duncan's multiple-range test at $5 \%$ probability level.

\section{RESULTS}

\section{Effect of desiccation on callus survival}

After two-week culture, new white or yellowish tissues formed around the callus indicated survival, while unviable calli turned brown after cryopreservation and thawing. With cryopreserved calli, regrowth changed with respect to desiccation duration and water content (Figure 1). Generally, to ensure cell survival after a freezing procedure, water content should be decreased to $20-25 \%$ of fresh weight (Bian et al., 2002). In this study, callus water content decreased dramatically after 20-min desiccation (Figure 1). The viability of dehydrated callus was $38.33 \%$ at the initial stage of desiccation $(0 \mathrm{~min})$; it increased to $52.72 \%$ as the water content declined from 92.3 to $74.2 \%$ after 20 -min desiccation, and the highest survival

Genetics and Molecular Research 15 (4): gmr15049342 
(68.89\%) was achieved with $57.3 \%$ water content after 30 -min desiccation. The viability then fell sharply to $40 \%$, at the water content of $40.7 \%$, after 40 -min desiccation, and the callus was not able to revive with a water content lower than $17 \%$ (60 min desiccation). In the first $30 \mathrm{~min}$, the viability of cryopreserved cells increased as the water content of the callus decreased, which suggested that a certain level of water loss could improve callus viability after cryopreservation. In contrast, no survival was found when the water content was too low. For most plant cells and organ cultures, damage during freezing is associated with intracellular ice formation in highly vacuolated cells, therefore, survival of cryopreserved organs could be rinsed by dropping the water content in cells (Popova et al., 2009). The water content of plant organs for optimal survival varies among plant species because of their differences in dehydration tolerance (Hitmi et al., 1999). Popova et al. (2009) reported that the highest post-cryopreservation survival rate $(23 \%)$ was obtained when calli were desiccated for $150 \mathrm{~min}$. Paulet et al. (1993) found that survival was similar for dehydration either by air drying or with silica gel, only if the optimum water content was achieved. We completely agree with this view, which can also be applied to calli during cryopreservation, as our study recorded the highest viability $(68.89 \%)$ with $57.3 \%$ water content after $30 \mathrm{~min}$ desiccation. In this study we favored air drying, since this method saves steps and can reduce pollution caused by additional components.

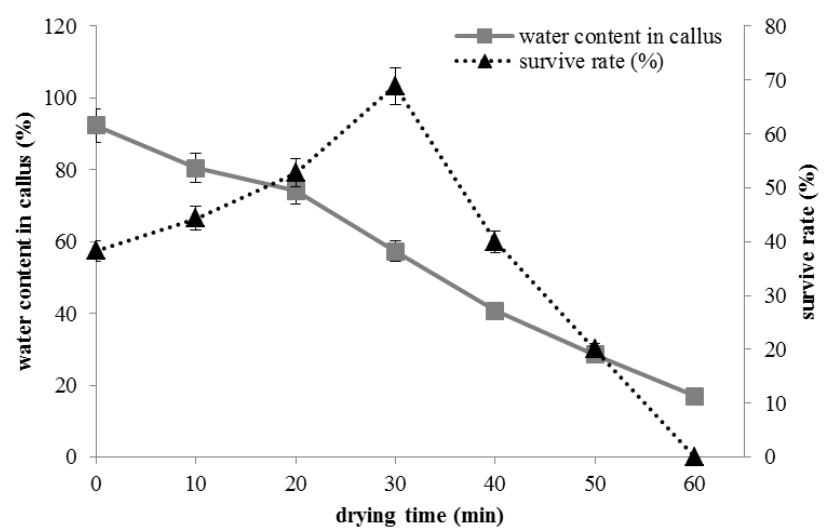

Figure 1. Changes in water content and viability of Schisandra chinensis calli after different desiccation durations.

\section{Effect of cryoprotectants and cryopreservation methods on callus viability}

In the case of vitrification, suitable cryoprotectants and cryopreservation method were very effective in enhancing callus survival. Dipping into S4 before slow freezing was conducive to survival (Table 1). In contrast, the survival rates of calli in S2 and S3 were much lower. With all cryoprotectants tested, slow freezing achieved the best survival, which was the most efficient method for callus survival. In contrast, step-wise freezing, including two cooling steps before placed the cryotubes into $-196^{\circ} \mathrm{C} \mathrm{LN}$, produced relatively low survival rates, ranging from 5.26 to $40 \%$. Our research highlighted the significance of precisely selecting cryoprotectants and freezing methods to optimize survival of $S$. chinensis calli after freezing. It has been shown previously that overexposure of cells to the vitrification solution could bring chemical toxicity (Rall, 1987). Mixed cryoprotectants are widely used in cryopreservation, and are able to neutralize cytotoxicity by decreasing the total concentration of cryoprotectants

Genetics and Molecular Research 15 (4): gmr15049342 
(Withers, 1985). The suitable time of exposure to cryoprotectants varies with plant species, and depends on the temperature during the exposure process (Niino et al., 1992; Nishizawa et al., 1993). Slow freezing allows a stepwise reduction to achieve low temperatures, and prevents a cooling-shock. Pérez et al. (1997) used embryogenic cells of Citrus spp, and found that dipping into liquid medium with $10 \%(\mathrm{v} / \mathrm{v}) \mathrm{DMSO}$, freezing by slow cooling, and then quick warming was beneficial to recovering viability. However, fast freezing by direct dipping into LN is widely used because of its simplicity (Grout, 2007). Shoot tips of Limonium serotinum treated with vitrification solution containing $30.0 \%$ glycerol, $20.0 \%$ DMSO, $20.0 \%$ ethylene glycol, and $15.0 \%$ sucrose (w/v), or $40.0 \%$ glycerol and $40.0 \%$ sucrose, achieved superior recovery, which reached $76 \%$ after cryopreservation by fast freezing (Barraco et al., 2011). Ben-Amar et al. (2013) obtained the highest recovery of embryogenic grapevine cells with a loading solution containing $0.4 \mathrm{M}$ sucrose and $2 \mathrm{M}$ glycerol, and rapid freezing. Among four cryoprotectants and three freezing methods in our study, the highest $S$. chinensis callus survival of $70.0 \%$ was achieved when loaded in $10 \%$ ethylene glycol, $8 \%$ glucose, and $10 \%$ DMSO wirh the slow freezing method.

Table 1. Effect of cryoprotectants and cryopreservation method on viability of Schisandra chinensis calli.

\begin{tabular}{l|l|c}
\hline Cryoprotectants & Cryopreservation method & Survival (\%) \\
\hline S1 (PVS2) & Slow freezing & $25.56^{\mathrm{f}}$ \\
& Step-wise freezing & $10.00^{\mathrm{i}}$ \\
& Fast freezing & $37.16^{\mathrm{e}}$ \\
\hline S2 (10\% DMSO+10\% sorbitol) & Slow freezing & $23.81^{\mathrm{g}}$ \\
& Step-wise freezing & $9.52^{\mathrm{i}}$ \\
& Fast freezing & $38.89^{\mathrm{d}}$ \\
\hline S3 (12.5\% DMSO+0.25\% CH) & Slow freezing & $15.00^{\mathrm{h}}$ \\
& Step-wise freezing & $5.26^{\mathrm{j}}$ \\
& Fast freezing & $26.32^{\mathrm{f}}$ \\
\hline S4 (10\% ethylene glycol+8\% glucose+10\% DMSO) & Slow freezing & $70.48^{\mathrm{a}}$ \\
& Step-wise freezing & $40.00^{\mathrm{c}}$ \\
\hline
\end{tabular}

Different letters within a column indicate a significant difference $(p<0.05)$ according to Duncan's multiple range test.

\section{Effect of thawing temperature on callus viability}

To further increase recovery after cryopreservation, the effect of rewarming on regeneration was examined (Figure 2A). Thawing methods markedly affected the recovery of cryopreserved calli. The regeneration rate of calli rapidly thawed in a water bath at $40^{\circ} \mathrm{C}$ for 2 min was significantly higher than that of calli maintained at $25^{\circ} \mathrm{C}$ or at $4{ }^{\circ} \mathrm{C}$ in a refrigerator. Thawing at $4{ }^{\circ} \mathrm{C}$ for $2 \mathrm{~h}$ and $25^{\circ} \mathrm{C}$ for 10 min gave 5 and $22.22 \%$ survival rates, respectively, compared with $70 \%$ survival for calli thawed at $40^{\circ} \mathrm{C}$ for $2 \mathrm{~min}$. In the reverse of the freezing process, transfer from a vitreous to a crystalline solution during thawing could cause a degree of damage to cells, and threaten the survival of meristems. Vitrified material from different species has its own optimal thaw temperature, such as $25^{\circ} \mathrm{C}$ for apple, pear, cherry, and sweet cherry (Niino et al., 1992), $30^{\circ} \mathrm{C}$ for tea (Kuranuki and Sakai, 1995), $35^{\circ} \mathrm{C}$ for mint (Towill, 1990), $40^{\circ} \mathrm{C}$ for white poplar (Lambardi et al., 2001), and $45^{\circ} \mathrm{C}$ for gooseberry and currant (Reed, 1995). The optimum thaw temperature for $S$. chinensis calli in our study was $40^{\circ} \mathrm{C}$, and this led to the production of new white or yellowish tissues. Therefore, rapidly thawing at $40^{\circ} \mathrm{C}$ for $2 \mathrm{~min}$ proved to be the best method for the recovery of $S$. chinensis calli. 
A

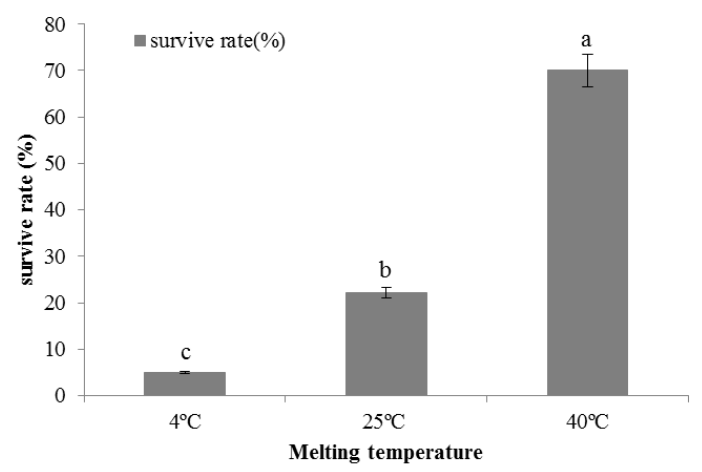

B

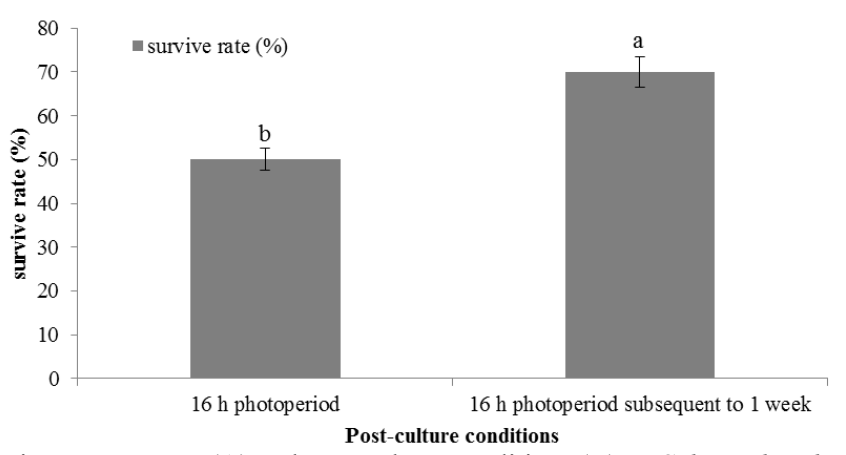

Figure 2. Effect of thawing temperature (A) and post-culture conditions (B) on Schisandra chinensis callus viability

\section{Effect of post-culture conditions on callus viability}

We studied the effect of dark culture after freezing on viability, and two different post-culture methods were assessed (Figure 2B). The best survival (70\%) was obtained by post-culturing in dark for 1 week, and then moving to light conditions (under 16-h photoperiod at $\left.36 \mu \mathrm{mol} \cdot \mathrm{m}^{-2} \cdot \mathrm{s}^{-1}\right)$. However, directly post-culturing under a $16-\mathrm{h}$ photoperiod at $36 \mu \mathrm{mol} \cdot \mathrm{m}^{-2} \cdot \mathrm{s}^{-1}$ caused a considerable reduction in callus survival, at only $50 \%$. Postculture also influenced regeneration of cryopreserved S. chinensis calli. Especially, darkness culture for a short time after thawing enhanced survival. An appropriate postculture condition is necessary for high survival and fast regrowth of the cryopreserved callus. Benson et al. (1989) reported that recovery could eventually occur in darkness, since dark incubation contributed to the avoidance of photooxidation phenomena, which could be harmful to the tissue. In this study, by testing the effects of two different postculture conditions on the recovery of cryopreserved $S$. chinensis calli, we found that the regeneration rate was markedly decreased without 1 week of dark culture. However, postculturing in dark for 1 week and then moving to light conditions greatly enhanced callus regeneration. Similar results have been found on protocorm-like bodies of $D$. candidum (Hong and Yin, 2009) and D. opposita (Li et al., 2009) after freezing, and this may have been due to damage repair of materials when cultured in darkness. Therefore, we

Genetics and Molecular Research 15 (4): gmr15049342 
confirmed that a period of dark culture, prior to light culture, is essential for the recovery of callus following cryopreservation.

\section{Somatic embryos induction and plantlet regeneration}

Embryogenic callus was formed from the callus samples after 4-week culture on MS with $1.0 \mathrm{mg} / \mathrm{L} \mathrm{TDZ}$ and $0.2 \mathrm{mg} / \mathrm{L} \mathrm{Zt} \mathrm{(Figure} 3 \mathrm{~A}$ ). Embryogenic calli were then moved to medium for somatic embryo induction. Global somatic embryos were formed after 1 month on $1 / 2 \mathrm{MS}$, and then developed into heart embryos, torpedo embryos, and cotyledon embryos in variable numbers (Figure 3B). Embryos were germinated (Figure 3C) and developed into whole plantlets (Figure 3D) within 2 months of culture.

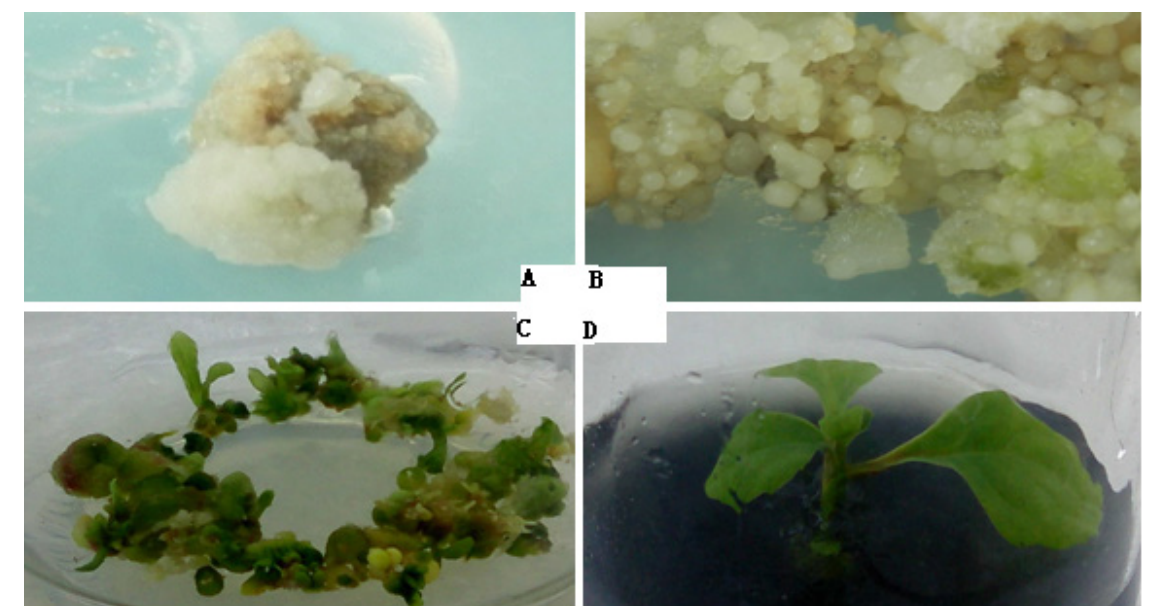

Figure 3. Schisandra chinensis plant regeneration. A. Embryogenic callus. B. Somatic embryos during different stages. C. Geminated embryos. D. Regenerated plantlet. (All bars =1 cm).

\section{Analysis of relative nuclear DNA content}

Relative nuclear DNA content of $S$. chinensis was detected by flow cytometry. The results indicated that the relative nuclear DNA content was not altered after cryopreservation (Figure 4). Plants regenerated through freezing can be evaluated at morphological, biochemical, chromosomal, and molecular levels (reviewed by Harding, 2004). In our study, all tested plants from both the untreated and the cryopreserved calli showed the same one peak of relative DNA content, which indicated the stability in genome size after cryopreservation. Recently, DNA flow cytometry analysis has been recognized as a convenient technique, due to its simplicity and reliability (Mikula et al., 2008). Similar studies showed that cryopreservation did not change the nuclear DNA content of proembryogenic cells and regenerated plants of G. tibetica and G. cruciata (Mikula et al., 2008). Consistence of relative DNA content had also been reported in Ginkgo biloba calli regenerated after cryopreservation (Popova et al., 2009).

Genetics and Molecular Research 15 (4): gmr15049342 


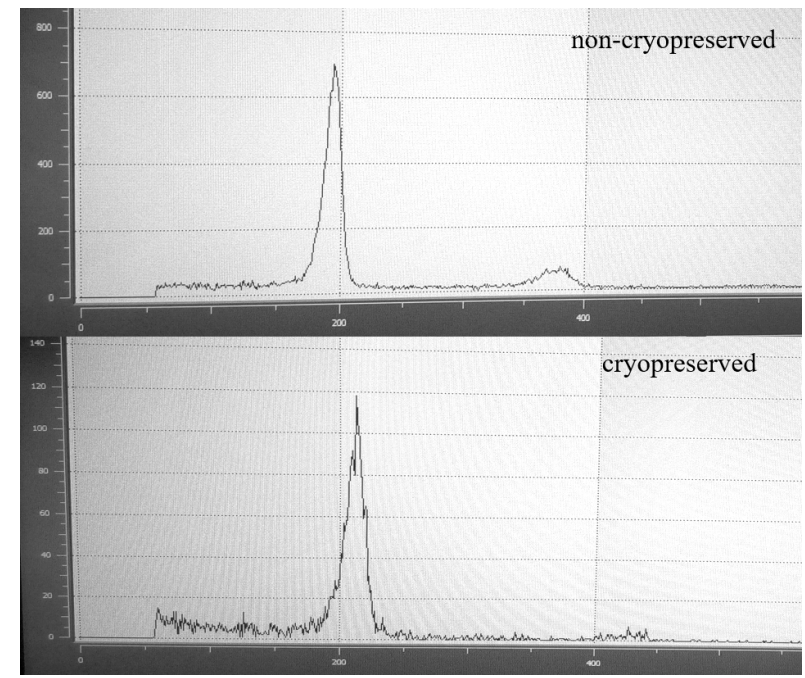

Figure 4. Relative DNA content of nuclei from plantlets regenerated from non-cryopreserved and cryopreserved calli of Schisandra chinensis.

\section{CONCLUSIONS}

In conclusion, a simple protocol for the cryopreservation of $S$. chinensis calli is described for the first time, focusing mainly on the most important aspects of this procedure: the survival of calli, and subsequent somatic embryogenesis and plant regeneration from cryopreserved calli. We also noted that the regenerated plants remained ploidy-stable after cryopreservation. However, further studies are necessary, with an emphasis on confirming the genetic stability of regenerated plantlets by biochemical and molecular analyses, to make sure that the procedure is applicable to $S$. chinensis germplasm conservations.

\section{ACKNOWLEDGMENTS}

Research supported by the Project of Science and Technology Department of Jilin Province (\#20130206014YY) and Project of Science and Technology Department of Jilin Province (\#20130305049YY).

\section{REFERENCES}

Baebler S̆, Hren M, Camloh M, Ravnikar M, et al. (2005). Establishment of cell suspension cultures of yew (Taxus X media REHD) and assessment of their genomic stability. In Vitro Cell. Dev. Biol. Plant 41: 338-343. http://dx.doi. org/10.1079/IVP2005642

Barraco G, Sylvestre I, Iapichino G and Engelmann F (2011). Cryopreservation of Limonium serotinum apical meristems from in vitro plantlets using droplet-vitrification. Sci. Hortic. 130: 309-313.

Ben-Amar A, Daldoul S, Allel D, Reustle G, et al. (2013). Reliable encapsulation-based cryopreservation protocol for safe storage and recovery of grapevine embryogenic cell cultures. Sci. Hortic. 157: 32-38. http://dx.doi.org/10.1016/j. scienta.2013.04.005

Benson EE, Harding K and Smith H (1989). Variation in recovery of cryopreserved shoot-tips of Solanum tuberosum exposed to different pre- and post-freeze light regimes. Cryo Lett. 10: 323-344.

Genetics and Molecular Research 15 (4): gmr15049342 
Bian HW, Wang JH, Lin WQ, Han N, et al. (2002). Accumulation of soluble sugars, heat-stable proteins and dehydrins in cryopreservation of protocorm-like bodies of Dendrobium candidum by the air-drying method. J. Plant Physiol. 159: 1139-1145. http://dx.doi.org/10.1078/0176-1617-00824

Chang GT, Kang SK, Kim JH, Chung KH, et al. (2005). Inhibitory effect of the Korean herbal medicine, Dae-Jo-Whan, on platelet-activating factor-induced platelet aggregation. J. Ethnopharmacol. 102: 430-439. http://dx.doi.org/10.1016/j. jep.2005.07.003

Chinese Pharmacopoeia Commission (2010). Pharmacopoeia of the People's Republic of China. Chinese Medical Science and Technology Press, Beijing, 61-62.

Engelmann F (1997). In vitro conservation methods. In: Biotechnology and plant genetic resources: conservation and use (Ford-Lloyd BV, Newburry JH and Callow JA, eds.). CABI, Wellingford, 119-162.

Engelmann F (2012). Germplasm collection, storage and preservation, In: Plant biotechnology and agriculture. prospects for the 21st Century (Altman A and Hazegawa PM, eds.). Academic Press, Oxford, 255-268.

Engelmann F and Engels JMM (2002). Technologies and strategies for ex situ conservation. In: Managing plant genetic diversity (Engels JMM, Rao VR, Brown AHD and Jackson MT, eds.). CABI, Wallingford and IPGRI, Rome, 89-104.

Grout BWW (2007). Cryopreservation of plant cell suspensions. In: Cryopreservation and Freeze-Drying Protocols (Day JG and Stacey GN, eds.). Humana Press Second Edition. Methods Mol. Biol. 368: 153-161.

Hancke JL, Burgos RA and Ahumada F (1999). Schisandra chinensis (Turcz.) Baill. Fitoterapia 70: 451-471. http://dx.doi. org/10.1016/S0367-326X(99)00102-1

Harding K (2004). Genetic integrity of cryopreserved plant cells: a review. Cryo Lett. 25: 3-22.

Hitmi A, Barthomeuf C and Sallanon H (1999). Cryopreservation of Chrysanthemum cinerariaefolium shoot tips. Effects of pretreatment conditions and retention of biosynthetic capacity. Cryo Lett. 20: 109-120.

Hong SR and Yin MH (2009). High-efficiency vitrification protocols for cryopreservation of in vitro grown shoot tips of rare and endangered plant Emmenopterys henryi Oliv. Plant Cell. Tiss. Org. 99: 217-226. http://dx.doi.org/10.1007/ s11240-009-9598-7

Ip SP and Ko KM (1996). The crucial antioxidant action of schisandrin B in protecting against carbon tetrachloride hepatotoxicity in mice: a comparative study with butylated hydroxytoluene. Biochem. Pharmacol. 52: 1687-1693. http://dx.doi.org/10.1016/S0006-2952(96)00517-5

Kuranuki Y and Sakai A (1995). Cryopreservation of in vitro-grown shoot tips of tea (Camellia sinensis) by vitrification. Cryo Lett. 16: 345-351.

Lambardi M, De Carlo A, Benelli C and Bartolini G (2001). Cryopreservation of woody species by vitrification of shoot tips and embryogenic tissue. Acta Hortic. 560: 125-128. http://dx.doi.org/10.17660/ActaHortic.2001.560.18

Li HJ, Guo YY, Jiang H, Wang YX, et al. (2009). Planting technical experience of Yanshan County early-maturing red bud taro on a large scale. China Agric. Technol. Extension. 25: 20-21.

Li Y, Xu C, Zhang Q, Liu JY, et al. (2005). In vitro anti-Helicobacter pylori action of 30 Chinese herbal medicines used to treat ulcer diseases. J. Ethnopharmacol. 98: 329-333. http://dx.doi.org/10.1016/j.jep.2005.01.020

Menges M and Murray JAH (2004). Cryopreservation of transformed and wild-type Arabidopsis and tobacco cell suspension cultures. Plant J. 37: 635-644. http://dx.doi.org/10.1046/j.1365-313X.2003.01980.x

Mikula A, Olas M, Sliwinska E and Rybczynski JJ (2008). Cryopreservation by encapsulation of Gentiana spp cell suspensions maintains regrowth, embryogenic competence and DNA content. Cryo Lett. 29: 409-418.

Min HY, Park EJ, Hong JY, Kang YJ, et al. (2008). Antiproliferative effects of dibenzocyclooctadiene lignans isolated from Schisandra chinensis in human cancer cells. Bioorg. Med. Chem. Lett. 18: 523-526. http://dx.doi.org/10.1016/j. bmcl.2007.11.082

Murashige T and Skoog F (1962). A revised medium for rapid growth and bio-assays with tobacco tissue cultures. Physiol. Plant. 15: 473-497. http://dx.doi.org/10.1111/j.1399-3054.1962.tb08052.x

Niino T, Sakai A, Yakuwa H and Nojiri K (1992). Cryopreservation of in vitro-grown shoot tips of apple and pear by vitrification. Plant Cell. Tiss. Org. 28: 261-266. http://dx.doi.org/10.1007/BF00036122

Nishizawa S, Sakai A, Amano Y and Matsuzawam T (1993). Cryopreservation of asparagus (Asparagus officinalis L.) embryogenic suspension cells and subsequent plant regeneration by vitrification. Plant Sci. 91: 67-73. http://dx.doi. org/10.1016/0168-9452(93)90189-7

Ohsugi M, Fan W, Hase K, Xiong Q, et al. (1999). Active-oxygen scavenging activity of traditional nourishing-tonic herbal medicines and active constituents of Rhodiola sacra. J. Ethnopharmacol. 67: 111-119. http://dx.doi.org/10.1016/ $\underline{\text { S0378-8741(98)00245-1 }}$

Paulet F, Engelmann F and Glaszmann JC (1993). Cryopreservation of apices of in vitro plantlets of sugarcane (Saccharum sp. hybrids) using encapsulation/dehydration. Plant Cell Rep. 12: 525-529. http://dx.doi.org/10.1007/BF00236101

Pérez RM, Navarro L and Duran-Vila N (1997). Cryopreservation and storage of embryogenic callus cultures of several Citrus species and cultivars. Plant Cell Rep. 17: 44-49. http://dx.doi.org/10.1007/s002990050349

Genetics and Molecular Research 15 (4): gmr15049342 
Popova EV, Lee EJ, Wu CH, Hahn EJ, et al. (2009). A simple method for cryopreservation of Ginkgo biloba callus. Plant Cell. Tiss. Org. 97: 337-343. http://dx.doi.org/10.1007/s11240-009-9522-1

Rall WF (1987). Factors affecting the survival of mouse embryos cryopreserved by vitrification. Cryobiology 24: 387-402. http://dx.doi.org/10.1016/0011-2240(87)90042-3

Reed BM (1995). Cryopreservation of in vitro-grown gooseberry and currant meristems. Cryo Lett. 16: 131-136.

Reed BM (2002). Implementing cryopreservation for long-term germplasm preservation in vegetativly propagated species. In: Biotechnology in Agriculture and Forestry. Vol. 50. Cryopreservation of Plant Germplasm II Towill, (L.E., Bajaj, Y.P.S. (ed.). Springer-Verlag, Berlin-Heidelberg. 22-31.

Sakai A, Kobayashi S and Oiyama I (1990). Cryopreservation of nucellar cells of navel orange (Citrus sinensis Osb. var. brasiliensis Tanaka) by vitrification. Plant Cell Rep. 9: 30-33. http://dx.doi.org/10.1007/BF00232130

Škrlep K, Bergant M, Winter GMD, Bohanec B, et al. (2008). Cryopreservation of cell suspension cultures of Taxus $\times$ media and Taxus floridana. Biol. Plant. 52: 329-333. http://dx.doi.org/10.1007/s10535-008-0067-7

Towill LE (1990). Cryopreservation of isolated mint shoot tips by vitrification. Plant Cell Rep. 9: 178-180. http://dx.doi. org/10.1007/BF00232174

Withers LA (1985). Cryopreservation of cultured plant cells and protoplasts. In: Cryopreservation of Plant Cells and Organs (Kartha K, ed.). CRC Press, Boca Raton, FI, 243-267.

Withers LA, Engels JMM (1990). The test tube genebank-a safe alternative to field conservation. IBPGR Newsl. for Asia, the Pacific and Oceania, 3: 1-2.

Zhang H, Wang WQ, Yang Q, Zhang Y, et al. (2007). Report on investigation of the resources of Schisandra chinensis (Turcz.) Baill in the northeast of China. Lishizhen Medicine and Materia Medica Research. 18: 1340-1341. 